\title{
3 Research Square \\ Creep Behavior of Polyamide 12, Produced By Selective Laser Sintering With Different Build Orientations
}

\author{
Maximilian Krönert ( $\square$ MaximilianKroenert@bundeswehr.org ) \\ Bundeswehr Research Institute for Materials Fuels and Lubricants: Bundeswehr \\ Wehrwissenschaftliches Institut fur Werk- und Betriebsstoffe Erding \\ Thomas Josef Schuster
}

Bundeswehr Research Institute for Materials

Felix Zimmer

Bundeswehr Research Institute for Materials

Jens Holtmannspötter

Bundeswehr Research Institute for Materials

\section{Research Article}

Keywords: Selective laser sintering, Polyamide 12, Creep, Burgers model

Posted Date: November 24th, 2021

DOI: https://doi.org/10.21203/rs.3.rs-1067750/v1

License: (c) (i) This work is licensed under a Creative Commons Attribution 4.0 International License. Read Full License 


\section{Abstract}

The successful use of components, produced by selective laser sintering as a rapid manufacturing process, requires a comprehensive understanding of the material. In this study, the effect of specimen build orientation on the mechanical properties of selective laser sintered polyamide 12 was investigated in detail. Samples were printed with an orientation of $0^{\circ}, 15^{\circ}, 45^{\circ}$ and $90^{\circ}$ to the build platform. Additionally to quasi-static tensile tests, Creep tests under different loads (5 MPa, $10 \mathrm{MPa}, 15 \mathrm{MPa}$ and $20 \mathrm{MPa}$ ) and for different times (10 hours and 1,000 hours) with and without relaxation were performed. Creep behavior was analyzed using the Burgers model. Therefore, the elastic strain, the relaxant strain, the viscous strain and the total deformation were determined. Results show that the build orientation has no significant influence on the long-term creep behavior, at small stresses. Short-term creep and relaxation tests show, that the elastic and viscous strain are only slightly influenced by the build orientation. However, the viscoelastic strain is affected by the build orientation. Furthermore, the deformations resulting from creep and relaxation have no significant influence on the mechanical behavior as shown by tensile tests.

\section{Introduction}

Additive manufacturing, also known as 3D-printing, is gaining increasing interest from academic institutions as well as from industry [1]. Selective laser sintering (SLS) is an additive manufacturing process in which a build area is successively coated with plastic powder. The applied powder particles are spatially resolved and fused homogeneously through the energy input of a laser [1-4]. Threedimensional components can be produced by superimposing and fusing many individual layers. Due to the high temperatures of build chamber and print bed, the non-sintered powder also serves as a support material, which leads to a great deal of design freedom for SLS-manufactured components [5]. In addition to the geometrical freedom, the SLS process also offers other advantages, such as the good mechanical properties of the printed products and the efficient use of the build chamber [5]. As a result, SLS has become a commonly used process in series production over the past few years [6].

In $2015,95 \%$ of all SLS components worldwide were made of polyamide 12 (PA12) [7]. Therefore, PA12 is the most used material on the SLS-market [8]. This results in many scientific reports dealing with the mechanical properties of PA12 produced by additive manufacturing including different types of quasistatic (tension as well as compression) and fatigue tests e.g. [9-14]. Many different factors, including build orientation, may influence the mechanical properties of PA12. Although many studies have investigated the influence of build orientation using different mechanical tests, the long-term behavior of PA12 SLS parts is still not fully understood $[10,15,16]$. In particular, there is a lack of knowledge regarding the creep behavior of PA12 SLS parts.

Thus, this study analyzes the long-term properties of SLS produced PA12 tensile specimens, specifically with respect to creep behavior. Creep is the strain as a function of time, as a result of a continual load [17, 18]. A study by Moeskops et al. indicated that PA12 processed by SLS is more sensitive to creep than 
many other thermoplastics and less sensitive than injection molded PA12 [16]. However, the influence of the build orientation on the creep behavior was not considered until. Therefore, in this study, the influence of the build orientation on the material behavior was investigated using not only quasi-static but also creep tests at room temperature.

\section{Experimental Procedure}

\subsection{Specimen fabrication}

For this study, SLS was used to produce tensile specimens with different orientations, Type 1A, according to DIN EN ISO 527-2 [19]. The marking was printed directly in the form of an embossing on the clamping surface of the test specimen.

The tensile specimens were manufactured in three production batches, using an EOS P396 selective laser sintering machine (EOS GmbH Electro Optical Systems, Krailling, Germany). In each print job, 20 test specimens were produced in each orientation. They were aligned at an angle of $0^{\circ}, 15^{\circ}, 45^{\circ}$ and $90^{\circ}$ oriented to the build plate, as shown in Fig. 2.

A standardized exposure parameter set was used for all samples (PA2200 Balance 1.0 - EOS). The scanning strategy of this parameter consists of one contour line with an alternating $x-y$ scanning pattern as hatch lines. This scanning strategy exposes the entire cross-sectional area of the specimen [20]. The layer thickness was $120 \mu \mathrm{m}$, the build chamber temperature $172^{\circ} \mathrm{C}$ and the removal chamber temperature $130^{\circ} \mathrm{C}$. Temperatures and therefore cooling rates were kept equal for all three batches to avoid changes in the crystallinity of PA12, which may affect the mechanical properties [21]. A mixture of $50 \%$ used and $50 \%$ new semi-crystalline polyamide 12 powder (PA2200) from EOS was used as sample material in order to secure process stability and repeatability $[22,23]$. The average particle volume diameter of the powder is $57 \mu \mathrm{m}$ [20]. The printed samples were blasted with glass beads and cleaned with compressed air. Finally, all 240 specimens were conditioned in a standard climate $\left(23^{\circ} \mathrm{C}, 50 \% \mathrm{RH}\right)$ for at least two weeks.

\subsection{Testing Methods}

To investigate the crystallinity of the samples, the Differential Scanning Calorimeter (DSC) technique was used $[24,25]$. Test specimens weighing $7 \pm 0.3 \mathrm{mg}$ were cut from the core of the Type $1 \mathrm{~A}$ specimens. Samples were subjected to a temperature scan from $25^{\circ} \mathrm{C}$ to $220^{\circ} \mathrm{C}$ at a heating rate of $10^{\circ} \mathrm{C} / \mathrm{min}$ under nitrogen atmosphere at a flow rate of $50.0 \mathrm{ml} / \mathrm{min}$. Temperature, time and heat flow were monitored. For each build orientation, at least five individual measurements were performed.

Tensile tests were carried out at room temperature with a universal testing machine according to DIN EN ISO 527-1 and -2 [19, 26]. Strain was measured using an extensometer with an initial gauge length of 50 $\mathrm{mm}$. Testing speed was set to $2 \mathrm{~mm} / \mathrm{min}$ according to DIN EN ISO 527-2. In total 61 tensile specimens with different orientations $\left(0^{\circ}, 15^{\circ}, 45^{\circ}\right.$ and $90^{\circ}$ concerning to the build direction) were tested. 
The creep and relaxation behavior was determined with a motorized creep testing machine according to DIN EN ISO 899-1 [27] at room temperature. Short-term creep (10 hours) and long-term creep (1,000 hours) with subsequent relaxation and different creep stresses (5 MPa, $10 \mathrm{MPa}, 15 \mathrm{MPa}, 20 \mathrm{MPa}$ ) were tested. In total, 52 samples with different orientations were tested.

The used testing methods are commonly used for additive manufactured material $[28,29]$.

\section{Results \& Discussion}

Crystallinity of the PA12 samples was determined from the heat flow - temperature - curves acquired using DSC. Fig. 3 shows the crystallinities as a function of the build orientation of the specimens. All orientations show a similar crystallinity. The average crystallinity for all samples is $31 \%$. Since crystallinity is comparable for all samples no effect on the mechanical behavior is to be expected resulting from the morphological structure.

Typical stress-strain curves from the tensile tests are shown in Fig. 4 for different build orientations. They show the highest maximum stress $\left(\sigma_{\mathrm{m}}\right)$ and highest maximum strain $\left(\varepsilon_{\mathrm{m}}\right)$ for samples built in $0^{\circ}$ direction. With increasing printing angle, maximum stress and highest maximum strain decrease. This is in line with studies of others $[15,16,21]$.

It is noticeable, that some (8 out of 16) of the samples printed with an $\mathrm{YZ}$ angle of $45^{\circ}$ and $90^{\circ}$ broke outside the parallel gage section, where strain measurement takes place. According to DIN EN ISO 527-2, these samples have to be assessed as invalid (these curves were marked with an *). YZ90 specimens, which broke within the strain measurement section (valid test) show a stress-strain curve which is comparable to the $\mathrm{YZ} 45^{\circ}$ specimens. However, $\mathrm{YZ90^{ \circ }}$ samples which broke outside this area (invalid test) show lower maximum stress and lower maximum strain. In table 1 the mean values for all samples, for the valid samples and the invalid samples are shown for $\mathrm{YZ} \mathrm{O}^{\circ}$ in comparison to the data provided in the manufacturers material data sheet [30]. If only the valid measurements are considered, it is noticeable that the tensile strength and elongation at break in particular are significantly greater than those given in the manufacturers material data sheet. These results from invalid samples fit with the ones given in the data sheet [30] and therefore seem to be typical for this material. Breaking typically took place here in the area of the beginning radius. This has already been reported in a similar form for samples produced by Fused Deposition Modeling (FDM) [31]. Sung-Hoon Ahn et al. justify this effect by the fact that stress concentrations occur at rounded corners. This is due to the FDM roads, which are discontinuous at these transitions. This influence of the FDM toolpath seems to be comparable to the laser guidance during the SLS process. Without taking into account valid and invalid specimens, the determination of the mean value therefore leads to an increase in the Young's modulus, tensile strength and elongation at break compared to the material data shoeet of the manufacuterer. However, this is also associated with an increase in the scatter of the results. Testing of samples $\mathrm{YZO}^{\circ}$ and $\mathrm{YZ} 5^{\circ}$ did not result in any invalid measurements. 
Table 1 Comparison of tensile test results considering all samples, only valid samples and invalid samples for $\mathrm{YZ} 90^{\circ}$ with the manufacturers material data sheet

\begin{tabular}{|l|l|l|l|l|l|}
\hline & Build orientation & Number of samples & Young's modulus [Mpa] & Tensile strength [Mpa] & Elongation at break [\%] \\
\hline Valid measurement & $\mathrm{YZ90}^{\circ}$ & 6 & $1616.6 \pm 82.7$ & $47.0 \pm 0.7$ & $14.5 \pm 2.7$ \\
\hline Invalid measurement & $\mathrm{YZ90^{ \circ }}$ & 5 & $1550.6 \pm 69.3$ & $42.9 \pm 0.9$ & $6.9 \pm 1.0$ \\
\hline Average value & $\mathrm{YZ90}$ & 11 & $1586.6 \pm 83.7$ & $45.1 \pm 2.2$ & $11.0 \pm 4.3$ \\
\hline Manufacturers specification & $\mathrm{YZ90}^{\circ}$ & - & 1650 & 42 & 4 \\
\hline
\end{tabular}

For a holistic representation, Fig. 5 shows the determined tensile strength and the Young's modulus as a function of the build orientation. The tensile strength as well as the Young's modulus decrease with increasing angle. This anisotropy coincides with the stress-strain curves of the performed tensile tests shown in Fig. 4.

In literature [32,33] differences in powder quality over build space are reported as explanation for an anisotropy. Since all specimens were manufactured with the same powder batch and the same mixing ratio, this can be excluded. Additionally, due to the comparable crystallinity for all samples a different composition of the amorphous and crystalline components can be excluded as reason for the anisotropy as well. The influence could therefore be due to the different sizes of the exposure areas. A larger YZ angle leads to a smaller exposure area, resulting in a decrease in strain and a decrease in strength [16].

To examine the initial creep and the subsequent relaxation, short-term creep tests were performed. The creep stress was set to $5 \mathrm{MPa}, 10 \mathrm{MPa}, 15 \mathrm{MPa}$ and $20 \mathrm{MPa}$. This stress was applied for 10 hours and then relieved $(0 \mathrm{MPa})$ for 10 hours. The results are shown in Fig. 6 . For better visibility, only one curve for each orientientation is shown here.

The results show a higher creep strain with increasing angle to the build direction. Similar effects can be observed after the relaxation, showing increased plastic deformation for increased angels. The variation within one series of specimen can be seen Fig. 7 showing the short-term creep curves under a stress of 20 MPa for all tested specimen.

These tests show a significant difference between the creep strain of the samples with $0^{\circ}, 45^{\circ}$ and $90^{\circ}$ to the build orientation. The result of the test specimens with an angle of $15^{\circ}$ show high variation but nevertheless confirm the statement that creep increases with the angle of build direction.

To describe the deformation behavior a 4-element / Burgers model [17] is used. The deformation is divided into three parts, which can be superimposed. The components are elastic deformation $\left(\epsilon_{0}\right.$, spontaneously reversible), viscoelastic or relaxed deformation $\left(\epsilon_{\text {rel }}\right.$, time-dependent reversible) and viscous deformation ( $\epsilon_{v}$, time-dependent irreversible). The material behavior is represented with a Maxwell and a Kelvin unit, which are connected in series (Fig. 8).

The model consists of a spring with the characteristic modulus of elasticity $\left(\mathrm{E}_{0}\right)$ and a dashpot, connected in series with the viscosity $\eta_{0}$. In addition, there is a parallel element made up of a spring $\left(E_{\text {rel }}\right)$ 
and a dashpot $\left(\eta_{\text {rel }}\right)$.

The deformation behavior under constant load $\left(\sigma_{0}\right)$ results for the respective strains $\left(\epsilon_{i}\right)$ as follow: elastic: $\epsilon_{0}=\frac{\sigma_{0}}{E_{0}}(1)$

viscoelastic/relaxant: $\epsilon_{\text {rel }}=\frac{1}{E_{r e l}}\left(1-e^{-\frac{t}{\tau}}\right) \sigma_{0}$ with $\tau=\frac{\eta_{\text {rel }}}{E_{\text {rel }}}$ (2)

viscous: $\epsilon_{v}=\frac{t \sigma_{0}}{\eta_{0}}(3)$

and the total deformation: $\epsilon_{t}=\epsilon_{0}+\epsilon_{r e l}(t)+\epsilon_{v}(t)(4)$

The Young's modulus, determined according to the DIN EN ISO 527-2, roughly corresponds to the value of $\left(E_{0}\right)$, if it is measured at very low loads and a test duration of less than one minute [17]. Therefore, the results from the tensile tests shown in Fig. 4 can be used to determine $E_{0}$ and the elastic strains $\left(\epsilon_{0}\right)$, which, are shown in Fig. 10b. The elastic strain increases with an increasing stress. However, the build orientation has no discernible influence on the elastic strain.

Using the equations stated above, the total $\left(\epsilon_{t}\right)$ and viscous elongation $\left(\epsilon_{v}\right)$ can be calculated from the short-term creep tests with subsequent relaxation. The proportions of the respective elongations are shown in Fig. 9.

Figure 10a and $\mathrm{d}$ show the total strain $\left(\epsilon_{t}\right)$ and the viscous strain $\left(\epsilon_{v}\right)$ as a function of the build orientation. The strain increases only slightly with increasing angle, only at a stress of $20 \mathrm{MPa}$ an significant increase can be observed.

The viscoelastic / relaxant part can be calculated according to equation 4 as the difference of elastic and viscous strain from the total strain, resulting in data shown in Fig. 10c. An increase in viscoelastic strain ( $\left.\epsilon_{r e l}\right)$ with increasing angle can be observed, in particular at a stress of $20 \mathrm{MPa}$.

Considering all three strains, it is noticeable that the elastic and viscous strains are only slightly affected by the build orientation. The viscoelastic strain is decisive in this case, leading to an increase in the total strain in the performed creep test. In the long-term behavior of SLS-produced PA12, the build orientation thus has the strongest influence on the viscoelastic strain.

In addition to the short-term tests, creep tests with a duration of 1,000 hours and different stresses were carried out (5 MPa, $10 \mathrm{MPa}, 15 \mathrm{MPa}, 20 \mathrm{MPa})$ using specimen with different build orientations $\left(0^{\circ}, 15^{\circ}\right.$, $\left.45^{\circ}, 90^{\circ}\right)$. The determined creep curves are shown in Fig. 11. The measured curves of the specimens with a build orientation of $0^{\circ}$ are comparable with the results from the literature [16, 34, 35]. After considering these results, the tendency for the increase in elongation with an increasing angle to the build direction is put into perspective. However, the results of the creep rupture tests show that this anisotropy, or the influence of the installation space orientation, has a much smaller effect during long-term loads. This 
seems to be due to the fact that the amorphous parts have enough time to adapt to the new stress state, especially for low stresses. There is apparently no directly recognizable influence of the exposure area.

To investigate the effect of deformation due to creep on the short-term material behavior, a combination of creep and quasi-static testing was performed. First, creep tests were performed on specimens for 1,000 hours at a stress of $20 \mathrm{MPa}$. These specimens were then relaxed for 200 hours ( $0 \mathrm{MPa}$ ). After relaxation quasi-static tensile tests were performed. The results of these quasi-static tests are shown in Fig. 12.

A comparison of the results with the tensile tests of the conditioned samples shows that creep and the associated deformations had no noticeable influence on the material behavior especially the elongation at break. The amorphous parts apparently had sufficient time to adapt to the viscous and viscoelastic deformation. Therefore, no disturbance remains in the material structure that affects the mechanical properties. Thus no noticeable effect on the material behavior can be observed in quasi-static tests performed after creep and relaxation. The viscoelastic component is also decisive for the anisotropic behavior in this case.

After the presentation and evaluation of the collected results, various statements can be formulated about the material behavior. These are summarized in the following paragraph.

The build orientation did not show noticeable influence on the long-term creep behavior in particular for small stresses. The viscoelastic strain is affected by the build orientation. As the exposure area decreases and the stress increases, the viscoelastic strain increases. The viscous strain increases with increasing stress, but is only slightly affected by the build orientation. The elastic strain increases with increasing stress and is independent of the build orientation.

Since build orientation only slightly affects the creep behavior and quasi-static mechanical properties do not change significantly due to creep and relaxation, SLS-processed PA12 can be rated as a well suited material for rapid manufacturing applications. Considering the design of parts, build orientation need to be considered but seems to be of less importance for parts mainly loaded with little load on a long period of time.

\section{Conclusion}

In the current study, tensile and creep tests were performed at room temperature on PA12 specimens manufactured by SLS with different build orientations. The evaluation was based on the experimental results and using the Burger Model.

The results of the tensile tests carried out show that the Young's modulus, the tensile strength as well as the elongation at break decrease with increasing angle. It was noticed that some of the specimens printed with an $\mathrm{YZ}$ angle of $45^{\circ}$ and $90^{\circ}$ were broken outside the parallel strain gauge area where the strain measurement takes place. This could be due to the laser guidance during the SLS process but will be topic of further studies 
After evaluating short-term creeped and relaxed specimens, it was found that the viscoelastic strain is most strongly influenced by the build orientation. This increases with a larger angle to the build platform. The elastic and viscous strains are only slightly affected by the build orientation, especially for small stresses. However, on the basis of the long-term creep tests performed, it was shown that the build orientation had no significant influence on the creep behavior at small stresses. It was also found that the deformations after creep and relaxation had no significant effect on the results in the quasi-static tensile test.

\section{Declarations}

The authors have no competing interests to declare that are relevant to the content of this article.
a. Funding - Not applicable
b. Clfocts of interest - Not applicable
c. Availability of data and material - Not applicable
d. Code availability - Not applicable
e. Ethics approval - Not applicable

\section{References}

1. Dizon JRC, Espera AH, Chen Q, Advincula RC (2017) Mechanical characterization of 3D-printed polymers.Addit. Manuf.20:44-47. https://doi.org/10.1016/j.addma.2017.12.002

2. Kruth JP, Wang $X$, Laoui T, Froyen $L$ (2003) Lasers and materials in selective laser sintering.Assem. Autom.23(4):357-371. https://doi.org/10.1108/01445150310698652

3. Goodridge RD, Tuck CJ, Hague RJM (2012) Laser sintering of polyamides and other polymers.Prog. Mater. Sci.57(2):229-267. https://doi.org/10.1016/j.pmatsci.2011.04.001

4. Nath SD, Nilufar S (2020) An Overview of Additive Manufacturing of Polymers and Associated Composites. Polymers 12(11):1-33. https://doi.org/10.3390/polym12112719

5. Schmid M (2015) Selektives Lasersintern (SLS) mit Kunststoffen, Technologie, Prozesse und Werkstoffe. Hanser

6. Leutenecker-Twelsiek B (2019) Additive Fertigung in der industriellen Serienproduktion: Bauteilidentifikation und Gestaltung. Dissertation, ETH Zürich

7. Schmid M (2015) Additive Fertigung mit Selektivem Lasersintern (SLS), Prozess- und Werkstoffüberblick. Springer Vieweg

8. Kiani A, Khazaee S, Badrossamay M, Foroozmehr E, Karevan M (2020) Investigation into Thermal History and Ist Correlation with Mechanical Probperties of PA12 Parts Produced by Selective Laesr Sintering Process. J Mater Eng Perform 29:832-840 
9. Walter R, Friedrich K, Gurka M (2018) Characterization of mechanical properties of additively manufactured polymers and composites. AIP Conf Proc 1981, 020033.

https://doi.org/10.1063/1.5045895

10. Feng L, Wang Y, Wei Q (2019) PA12 Powder Recycled from SLS for FDM.Polymers11(4):727. https://doi.org/10.3390/polym11040727

11. Van Hooreweder B, De Coninck F, Moens D, Boonen R, Sas P (2010) Microstructural characterization of SLS-PA12 specimens under dynamic tension/compression excitation.Polym. Test.29(3):319-326. https://doi.org/10.1016/j.polymertesting.2009.12.006

12. Schob D, Sagradov I, Roszak R, Sparr H, Franke R, Ziegenhorn M, Kupsch A, Léonard F, Müller BR, Bruno $G$ (2019) Experimental determination and numerical simulation of material and damage behaviour of 3D printed polyamide under cyclic loading. Arch Mech 71(4-5):507-526

13. Stoia DI, Linul E, Marsavina L (2019) Influence of Manufacturing Parameters on Mechanical Properties of Porous Materials by Selective Laser Sintering.Materials12(6):871. https://doi.org/10.3390/ma12060871

14. Salmoria GV, Leite JL, Vieira LF, Pires ATN, Roesler CRM (2012) Mechanical properties of PA6/PA12 blend specimens prepared by selective laser sintering.Polym Test31:411-416. https://doi.org/10.1016/j.polymertesting.2011.12.006

15. Caulfield B, McHugh PE, Lohfeld S (2007) Dependence of mechanical properties of polyamide components on build parameter in the SLS process.J Mater Process Technol182(1-3):477-488. https://doi.org/10.1016/j.jmatprotec.2006.09.007

16. Moeskops E, Kamperman N, van de Vorst B, Knoppers R (2004) Creep Behaviour of Polyamide in Selective Laser Sintering. TNO Industrial Technology

17. Ehrenstein GW (2011) Polymer-Werkstoffe, Struktur - Eigenschaften - Anwendungen. Carl Hanser

18. Laurence WMcK (2015) The Effect of Creep and other Time Related Factors on Plastics and Elastomers. William Andrew

19. DIN EN ISO 527-2 (2012) Plastics - Determination of tensile properties - Part 2: Test conditions for moulding and extrusion plastics. Beuth

20. Liebrich A, Langowski HC, Schreiber R, Pinzer BR (2020) Permeation Properties of Laser-Sintered Polyamide 12 Sheets in Comparison to an Extruded Polyamide 12 Film.. In: In: Hopmann C, Dahlmann R (eds) Advances in Polymer Processing 2020. Springer Vieweg, Berlin

21. Kiani A, Khazaee S, Badrossamay M, Foroozmehr E, Karevan M (2020) An Investigation into Thermal History and Its Correlation with Mechanical Properties of PA12 Parts Produced by Selective Laser Sintering Process.J Mater Eng Perform29:832-840. https://doi.org/10.1007/s11665-020-04640-0

22. Kruth JP, Levy G, Klocke F, Childs THC (2007) Consolidation phenomena in laser and powder-bed based layered manufacturing.CIRP Ann56(2):730-759. https://doi.org/10.1016/j.cirp.2007.10.004

23. EOS GmbH - Electro Optical Systems (2017) Parameter data sheet, Maschinen-, Software- und Materialparameter, EOSP396/PSW3.8. EOS GmbH 
24. DIN EN ISO 11357-1 (2017) Plastics - Differential scanning calorimetry (DSC) - Part 1: General principles. Beuth

25. DIN EN ISO 11357-3 (2018) Plastics - Differential scanning calorimetry (DSC) - Part 3:

Determination of temperature and enthalpy of melting and crystallization. Beuth

26. DIN EN ISO 527-1 (2012) Plastics - Determination of tensile properties - Part 1: General principles. Beuth

27. DIN EN ISO 899-1 (2013) Plastics - Determination of creep behaviour - Part 1: Tensile creep. Beuth

28. DIN EN ISO 17296-3 (2016) Additive Manufacturing - General principles - Part 3: Main characteristics and corresponding test methods. Beuth

29. Forster A (2015) Materials Testing Standards for Additive Manufacturing of Polymer Materials: State of the Art and Standards Applicability. NISTIR 8059. Mhttps://doi.org/10.6028/nist.ir.8059

30. EOS GmbH - Electro Optical Systems (2018) Material data sheet, PA 2200 Balance 1.0. https://eos.materialdatacenter.com. Accessed 13 August 2021

31. Ahn S, Montero M, Odell D, Roundy S, Wright PK (2002) Anisotropic material properties of fused deposition modeling ABS.Rapid Prototyp J8(4):248-257.

https://doi.org/10.1108/13552540210441166

32. Choren J, Gervasi V, Herman T, Kamara S, Mitchell J (2001) SLS Powder Life Study. Solid Freeform Fabrication Symposium. http://dx.doi.org/10.26153/tsw/3234

33. Gornet TJ, Davis KR, Starr TL, Mulloy KM (2002) Characterization of Selective Laser Sintering Materials to Determine Process Stability. Solid Freeform Fabrication Symposium. http://dx.doi.org/10.26153/tsw/4531

34. EOS GmbH - Electro Optical Systems (2001) Product information, EOSINT P/PA2200-Pulver. EOS $\mathrm{GmbH}$

35. Mohammadizadeh M, Fidan I, Allen M, Imeri A (2018) Creep behavior analysis of additively manufactured fiber-reinforced components. Int J Adv Manuf Technol99:1225-1234. https://doi.org/10.1007/s00170-018-2539-z

\section{Figures}




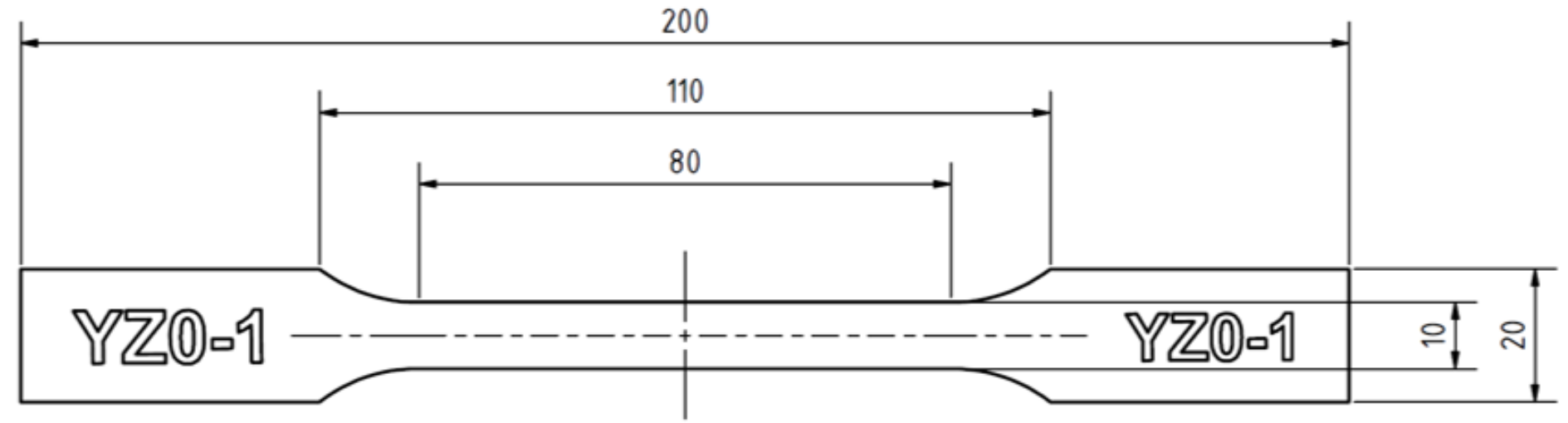

thickness $=4$

\section{Figure 1}

Dimensions, in millimeters, of the labeled 1A tensile specimens, according to DIN EN ISO 527-2 [20]
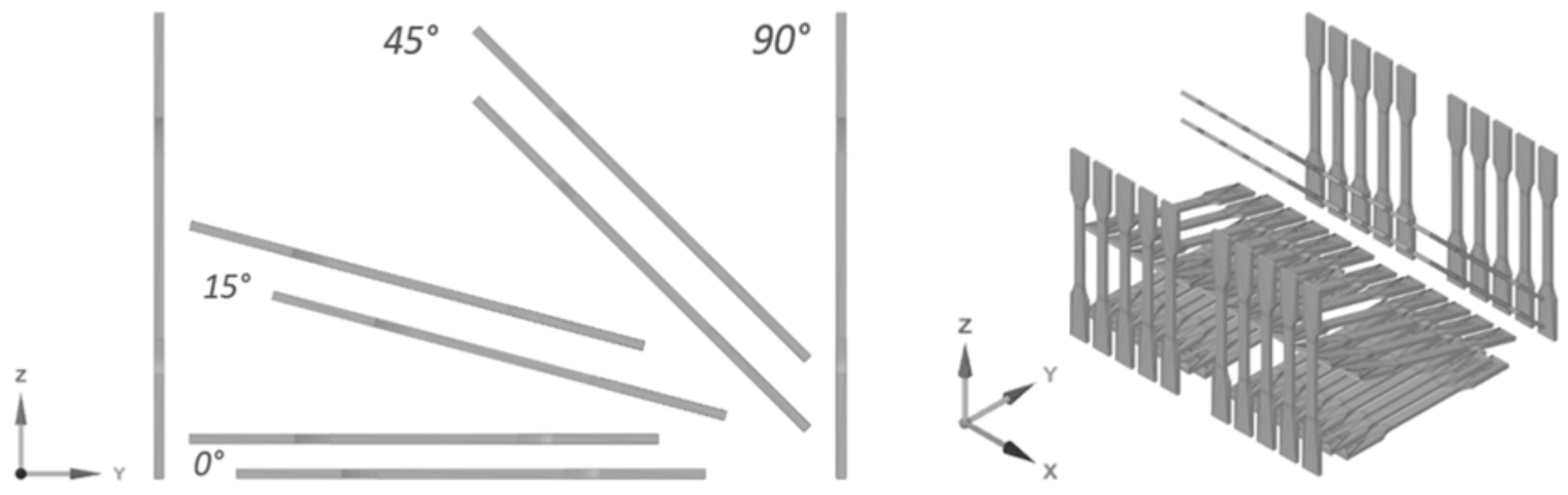

Figure 2

Schematic of the specimen orientation $\left(0^{\circ}, 15^{\circ}, 45^{\circ}\right.$ and $90^{\circ}$ concerning to the build direction) and the build job configuration of one of the three print jobs. 


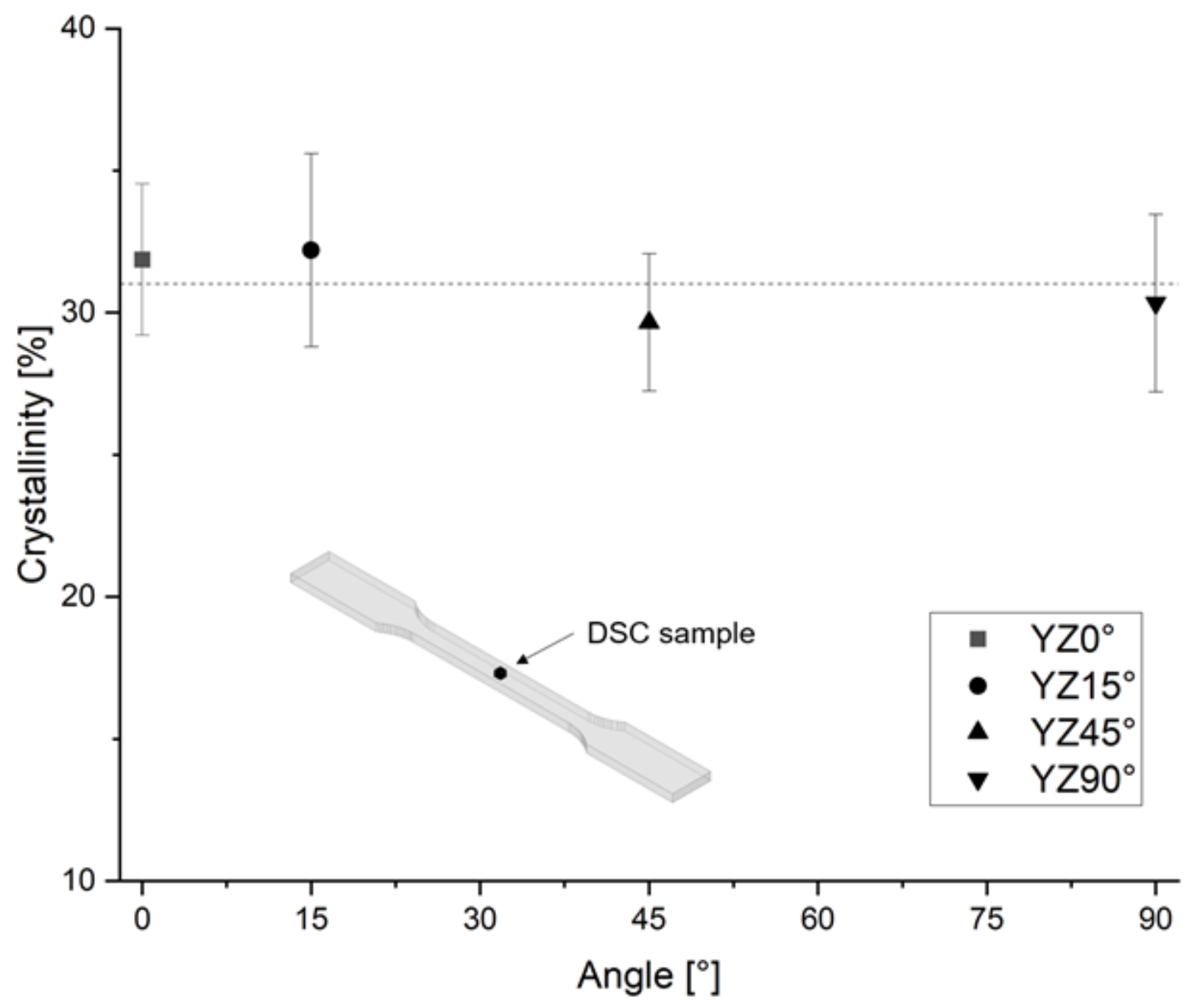

Figure 3

Determined crystallinity of SLS manufactured PA12 with different build orientations 


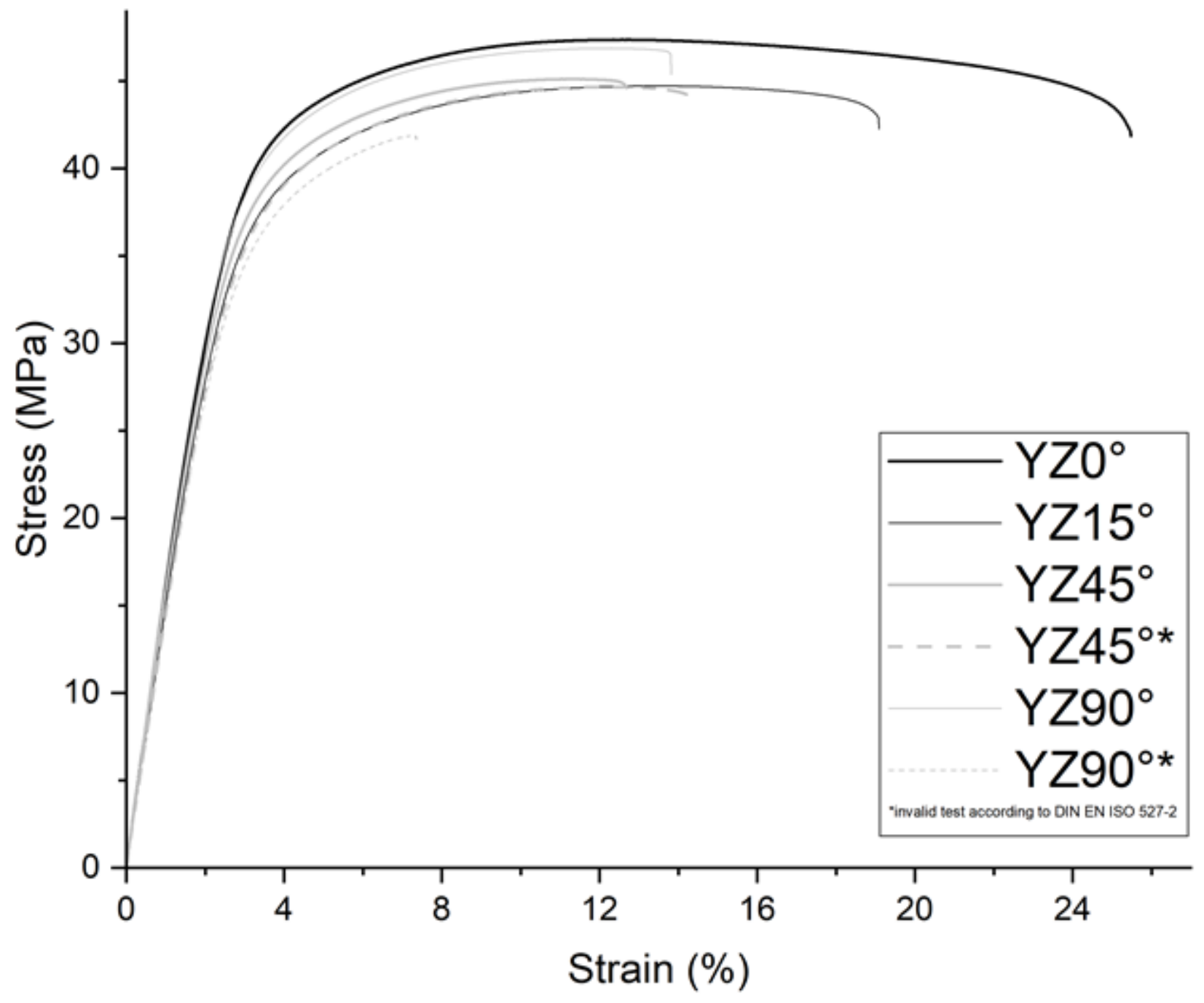

Figure 4

Samples with different orientation to the build direction and their tensile behavior at room temperature 


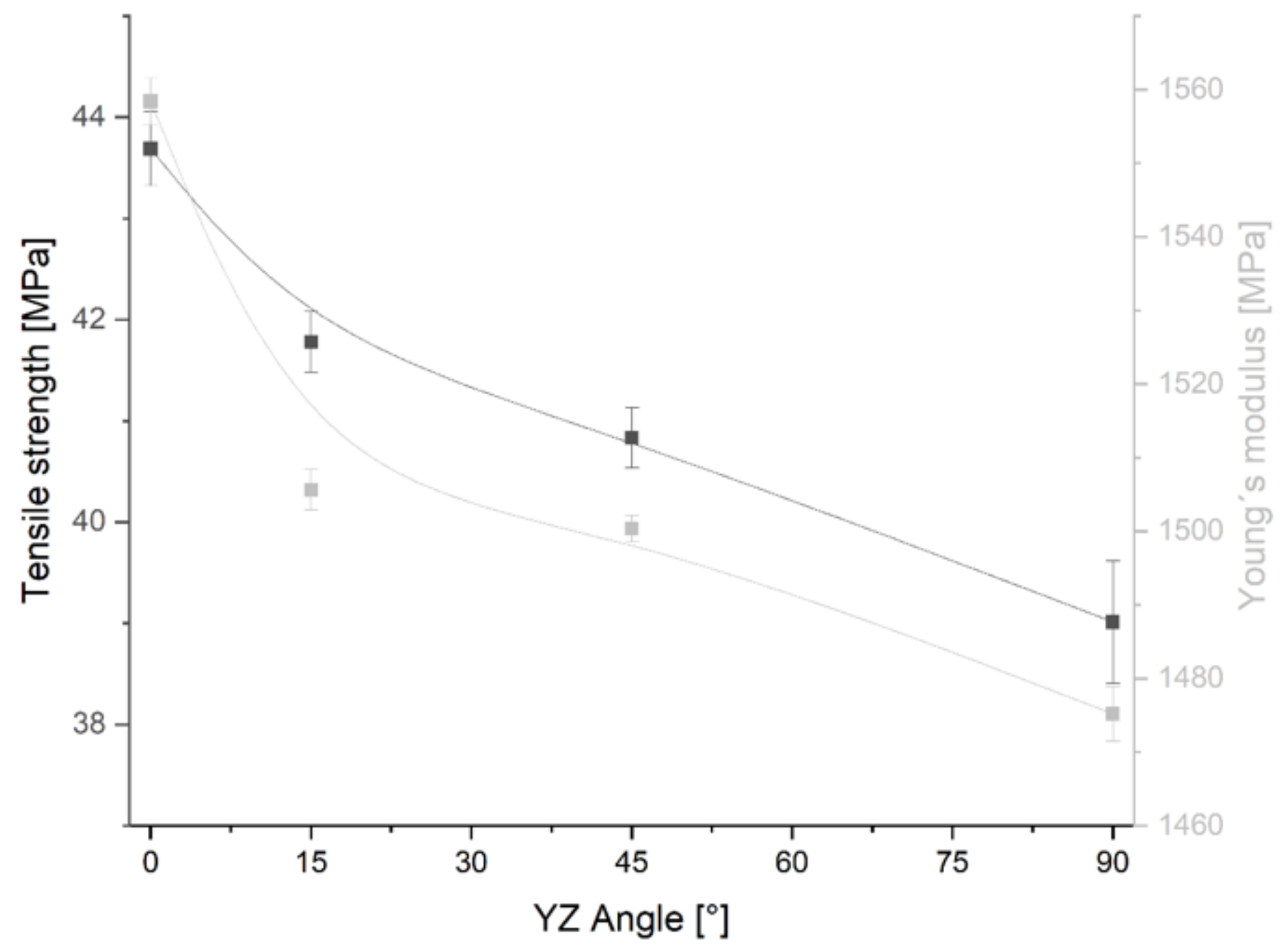

Figure 5

Representation of the determined tensile strength and Young's modulus as a function of the build orientation 


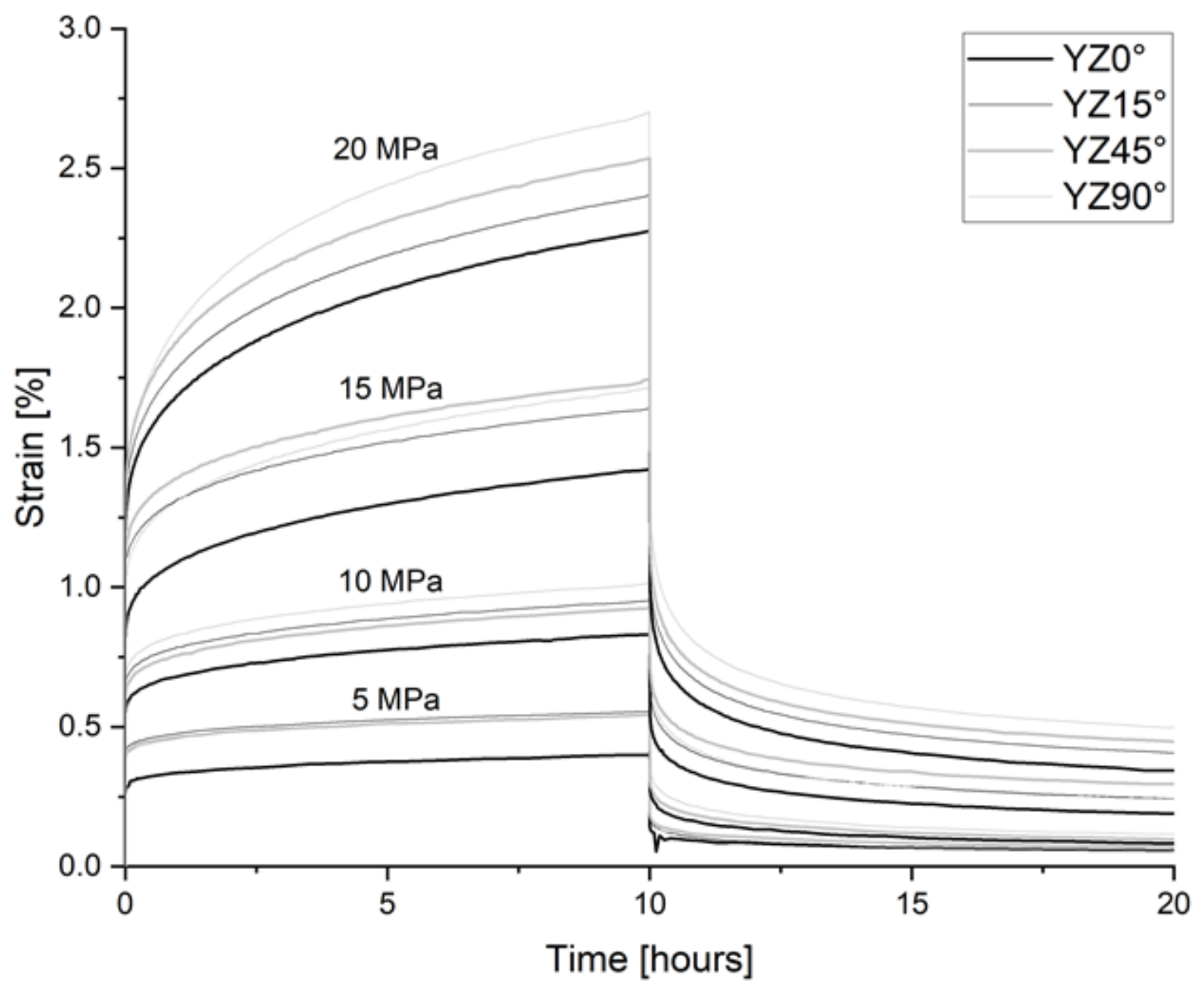

Figure 6

Short-term creep of differently oriented samples with different creep stresses 


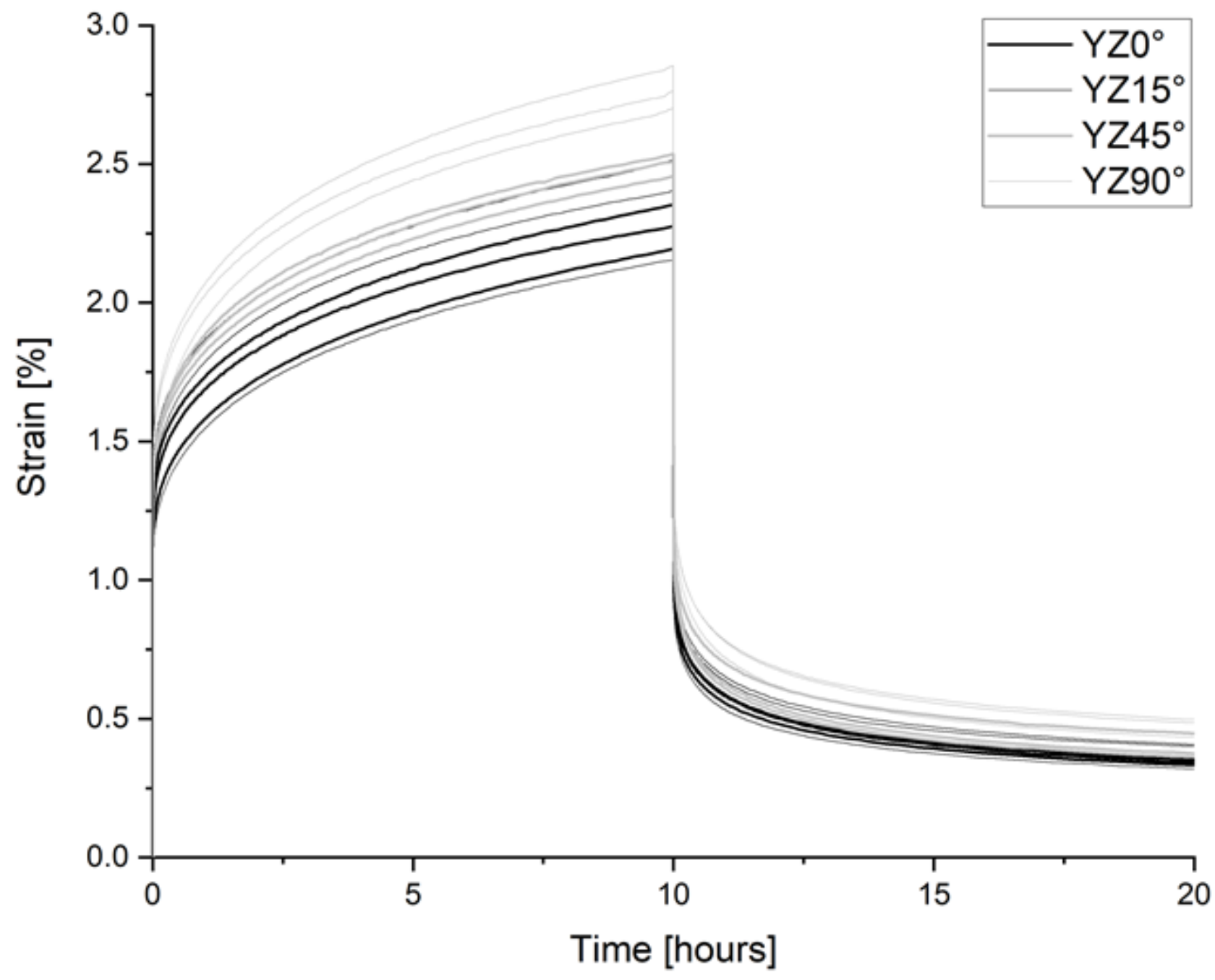

Figure 7

Short-term creep behavior of differently oriented samples under $20 \mathrm{MPa}$ load

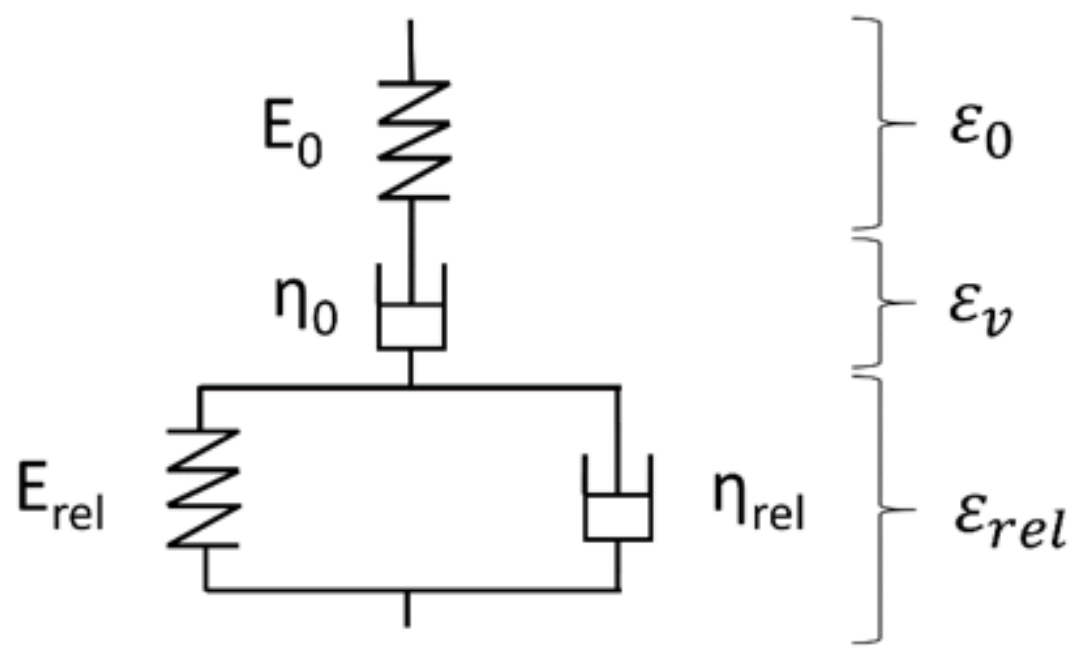

Figure 8 
Schematic diagram of the four-element model (index: $0=$ elastic, $v=$ viscous, rel $=$ relaxant)

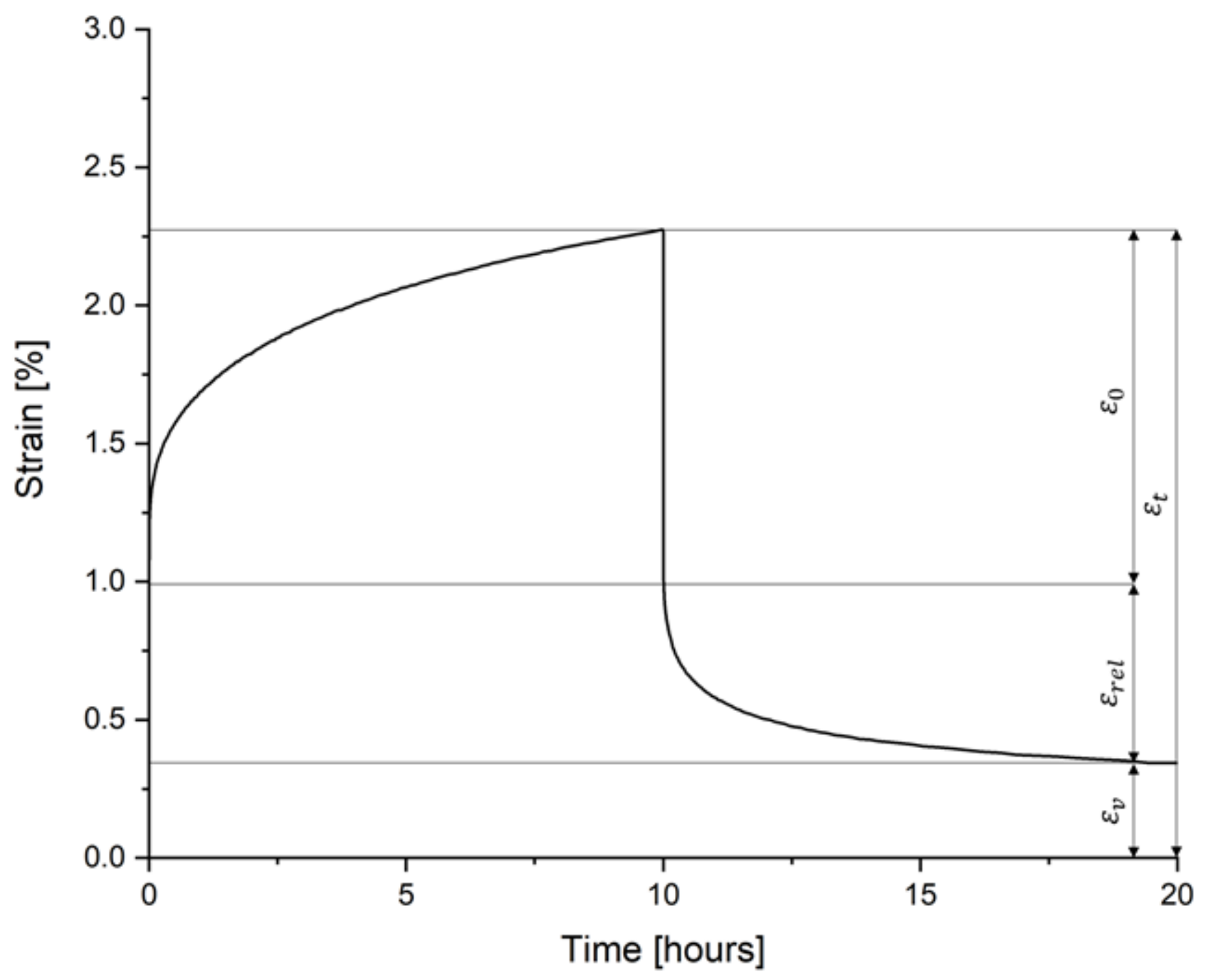

Figure 9

Short-term creep behavior of an $\mathrm{YZO} 0^{\circ}$ specimen under $20 \mathrm{MPa}$ load 

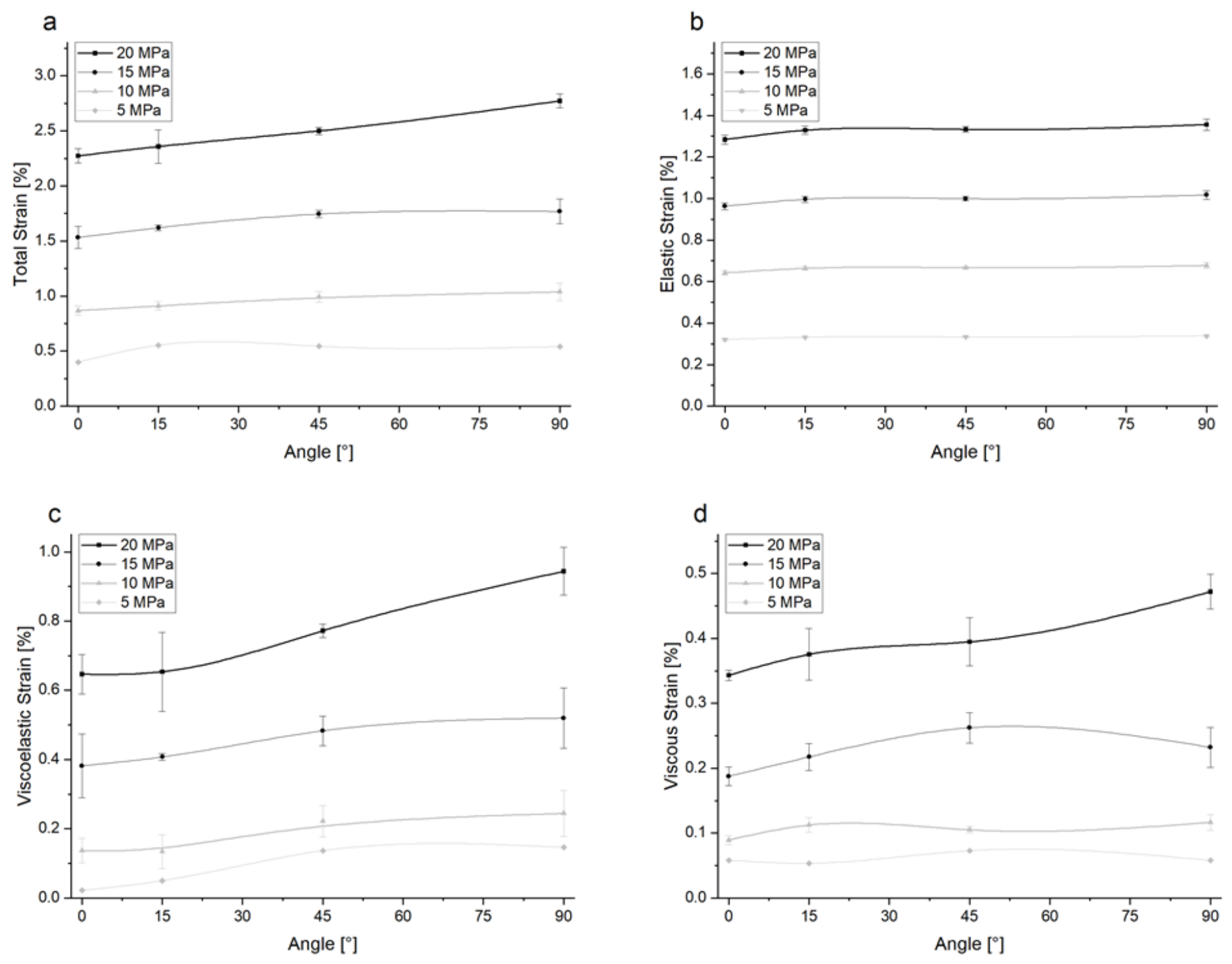

\section{Figure 10}

Elongations after 10 hours of creep with different loads and orientations oft he specimens. a Total Strain. b Elastic Strain. c Viscoelastic Strain. d Viscous Strain 


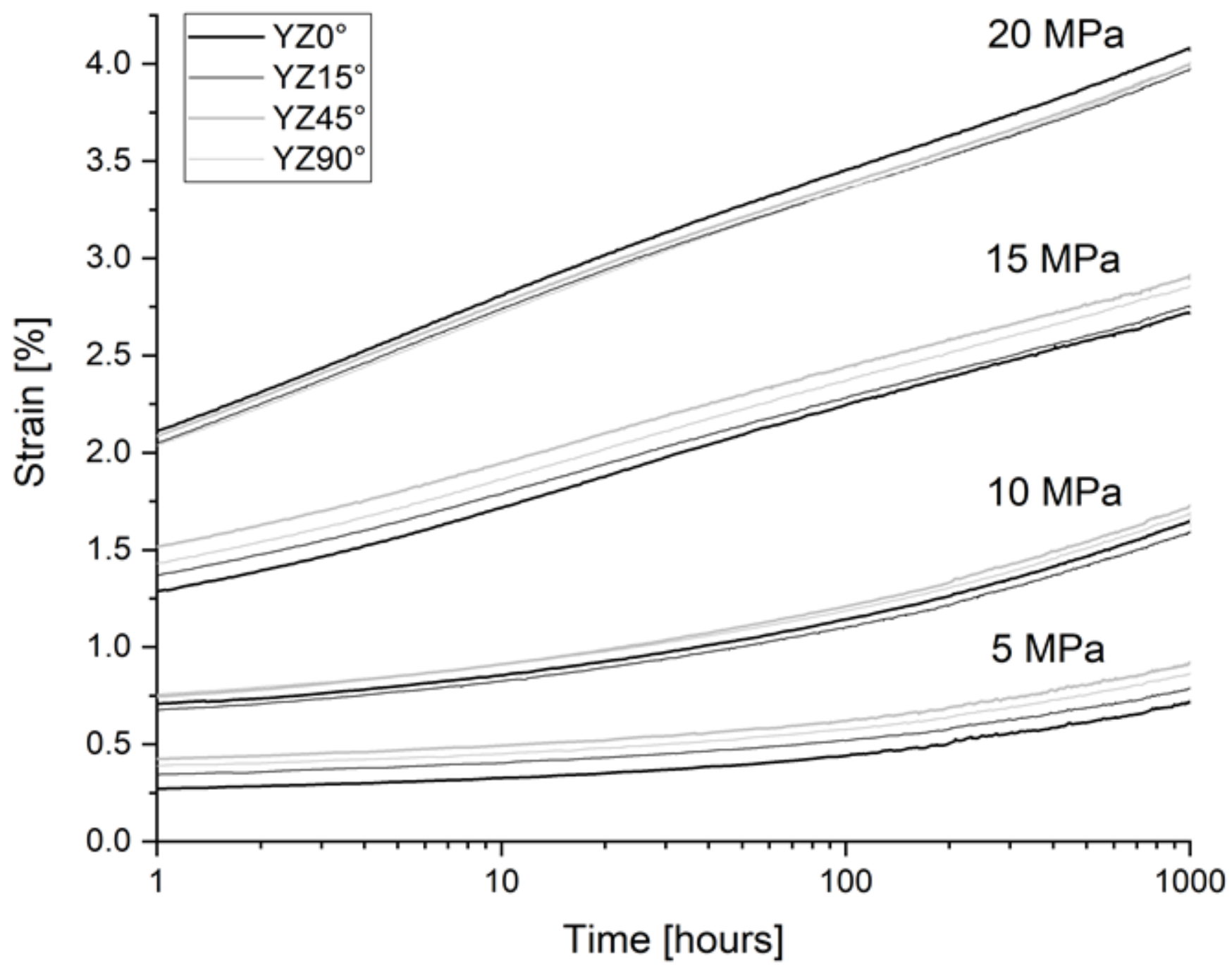

Figure 11

Long-term behavior of tensile specimens made of PA12, which were manufactured by SLS in different build orientations. The tests were carried out in a standard climate $\left(23^{\circ} \mathrm{C}, 50 \% \mathrm{RH}\right)$ with different creep stresses. 


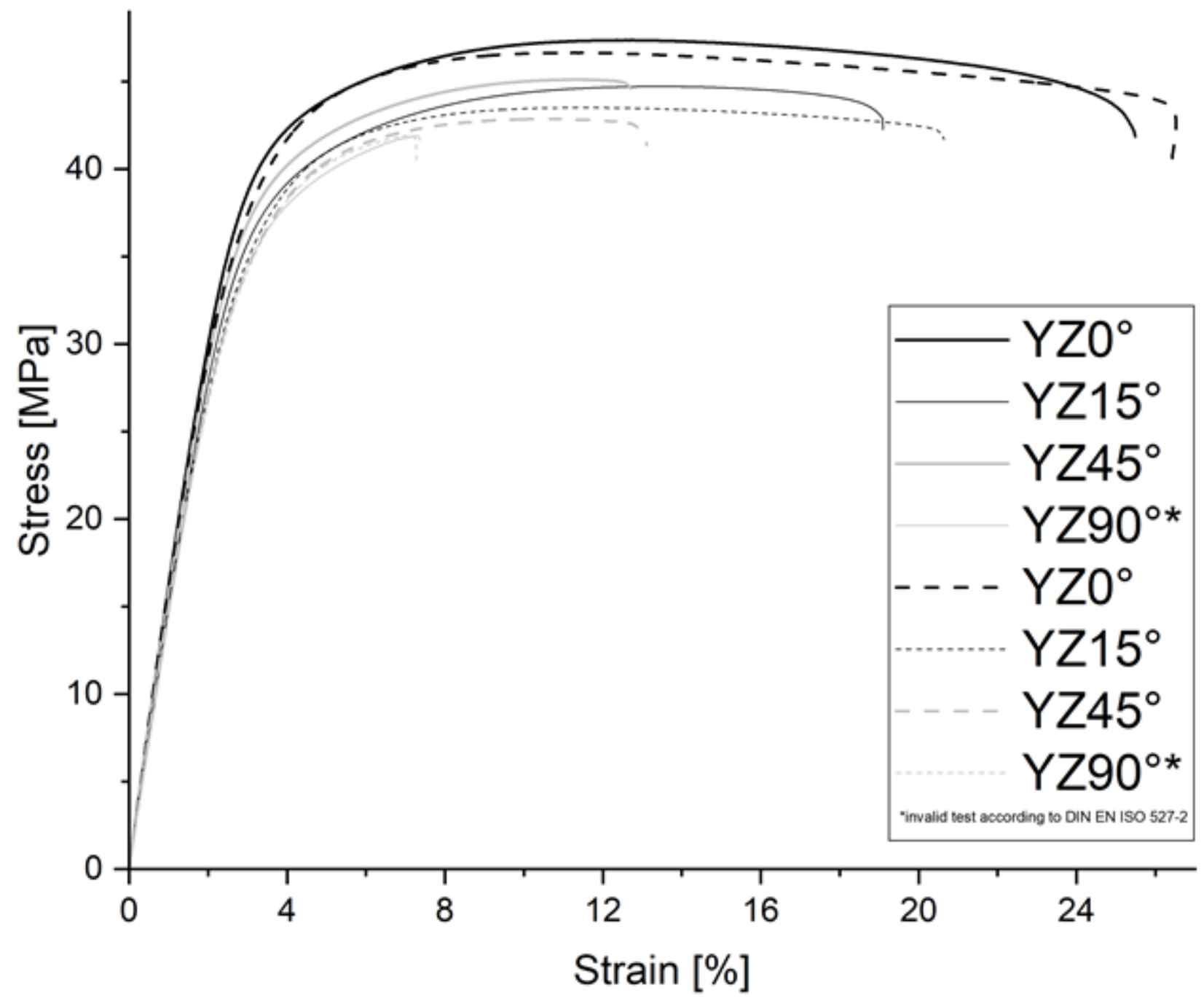

Figure 12

Tensile tests with different installation space orientations, which were tested after 1,000 hours creeping at $20 \mathrm{MPa}$ and subsequent relaxation (shown with dashed lines). The results of the tensile tests on the initial specimens are shown with solid lines. 